\title{
Impacts of Weather on Public Transport Ridership: Results from Mining Data from Different Sources
}

\author{
Meng ZHOU ${ }^{\mathrm{a}, \mathrm{b}}$, Donggen WANG ${ }^{\mathrm{a}}$, Qingquan LI $^{\mathrm{b}}$, Yang YUE ${ }^{\mathrm{b}}$, Wei TU ${ }^{\mathrm{b}}$, Rui CAO ${ }^{\mathrm{b}}$
}

\begin{abstract}
The existing studies concerning the influence of weather on public transport have mainly focused on the impacts of average weather conditions on the aggregate ridership of public transit. Not much research has examined these impacts at disaggregate levels. This study aims to fill this gap by accounting for intra-day variations in weather as well as public transport ridership and investigating the effect of weather on the travel behavior of individual public transit users. We have collected smart card data for public transit and meteorological records from Shenzhen, China for the entire month of September, 2014. The data allow us to establish association between the system-wide public transit ridership and weather condition on not only daily, but also hourly basis and for each metro station. In addition, with the detailed trip records of individual card holders, the travel pattern by public transit are constructed for card holders and this pattern is linked to the weather conditions he/she has experienced. Multivariate modeling approach is applied to analyze the influence of weather on public transit ridership and the travel behavior of regular transit users. Results show that some weather elements have more influence than others on public transportation. Metro stations located in urban areas are more vulnerable to outdoor weather in regard to ridership. Regular transit users are found to be rather resilient to changes in weather conditions. Findings contribute to a more in-depth understanding of the relationship between everyday weather and public transit travels and also provide valuable information for short-term scheduling in transit management.
\end{abstract}

Keywords: weather condition, public transit, ridership, smart card data, Shenzhen

\section{INTRODUCTION}

Transportation is an activity that has to be exposed to outdoor environment where weather is a major defining factor. Weather conditions impact both the performance of transportation systems and the travel behavior of passengers. Bad weather conditions may degrade the level of service of transportation systems (Hofmann and O'Mahony, 2005); likewise, different weather conditions may influence passengers' choice of departure time and transport mode or even whether or not to conduct a trip at all (De Palma and Rochat, 1999). Accordingly, two major themes of studies on the impact of weather on transportation can be identified. The first stream of studies investigate the influence of weather on the performance of transport systems including infrastructure performance (Koetse and Rietveld, 2009), road capacity and vehicle moving speed (Kyte et al., 2001; Smith et al., 2004) and disruptions in the transport systems caused by adverse weathers (Hofmann and O'Mahony, 2005). The second stream of studies has focused on the impact of weather on the travel behavior of passengers. These include studies on the impact of weather conditions on travel demand (Cools et al., 2010), modal shift (Heinen et al., 2010; Koetse and Rietveld, 2009), and route and destination choices (Cools et al., 2010). These studies have covered different weather elements and targeted various transport modes and systems. Studies have investigated the link between the seasonal fluctuation of temperature and the shift pattern of transport mode (Muller et al., 2008); the association between vehicle traffic volume and weather conditions such as coldness (Tang and Thakuriah, 2012) and snow 
and heavy wind (Maze et al., 2006). The influence of weather on the usage of active transport modes including cycling has also attracted quite some research attention (Nankervis, 1999; Bergström and Magnusson, 2003; Brandenburg et al., 2004).

The influence of weather on public transportation, on the other hand, has received relatively less attention. One of the reasons could be that the effect of weather on public transit is more complex than private and non-motorized transport modes. Transit riders are subject to the weather effect in a similar way like active transport mode users on the way to/from transit facilities and private transport mode users when on-board the vehicle (Guo et al., 2007). In addition, bad weather may reduce the desire to travel in general and, in turn, demand for public transit; it may also divert the travel demand from other transport modes (e.g., cycling) to public transit (Khattak, 1991). Probably constrained by the availability of data, the existing studies on the weather influence on public transit have mainly focused on the effect of average weather conditions on the aggregate ridership of public transit on daily basis (e.g., Guo et al., 2007; Stover and McCormack, 2012). As a result, these studies do not account for intra-day variations in weather as well as ridership and thus fail to establish direct links between weather conditions and demand for public transit at finer temporal scales. In addition, they do not investigate the effect of weather on the travel behavior of individual public transit users. Exploring the impact of weather on public transit at fine-grained temporal and spatial scales would be not only of great importance to our understanding of the relationship between weather and travel behavior but also very helpful for developing short-term transit management measures to enhance resilience to weather changes.

This study aims to fill these research gaps and enrich the existing literature with more findings on the influence of weather on public transportation. We have collected smart card data for public transit and meteorological records from Shenzhen, China for the entire month of September, 2014. The data allow us to establish association between the system-wide public transit ridership and weather condition on not only daily, but also hourly basis and for each metro station. In addition, with the detailed trip records of individual card holders, the travel pattern by public transit can be constructed for each card holder and this pattern can be linked to the weather conditions he/she has experienced. Multivariate modeling approach is applied to analyze the influence of weather on public transit ridership and the travel behavior of regular transit users. Results show that some weather elements are more influential than others on public transportation. Metro stations located in urban areas are more vulnerable to bad weather with regard to ridership. Regular transit users are found to be rather resilient to changes in weather conditions. Findings of this study contribute to a more in-depth understanding of the relationship between weather and travel by public transit and also provide valuable information for short-term scheduling in transit management.

The remainder of this paper is organized as follows. Section 2 reviews related studies and provides the literature background for the present study. Section 3 introduces the data and the study area. Analytical approaches are also elaborated on in Section 3. Section 4 presents and discusses the analysis results and research findings. Section 5 summarizes the research findings and points out future research directions.

\section{RELATED WORKS}

The transportation impacts of weather have received substantial research attention. Studies have investigated the influence of weather types (e.g., snowy or rainy day) and elements (e.g., wind, temperature, and precipitation) on various aspects of transportation including system-wide performance and trip-making behavior of travelers. In this section, we shall review the relevant studies, outline the major findings and identify the research gaps.

\subsection{Impact of weather on traffic and urban transportation}


A number of studies have examined the impact of weather on urban transportation systems and travel demand and different weather elements have been reported to have different effects. Several studies have found negative effect of precipitation, either snow or rainfall, on outdoor activity and travel demand (Spinney and Millward, 2011; Chan and Ryan, 2009; Tucker and Gilliland, 2007). In addition, total traffic volume on urban highways and intra-urban roads are reported to be reduced by snow (Call, 2011; Datla and Sharma, 2010) or rainfall (Al Hassan and Barker, 1999; Keay and Simmonds, 2005). Other studies have reported opposite results where rainfall or snow increased motorized travel volume (Aaheim and Hauge, 2005; Saneinejad et al., 2012). Temperature and wind are other elements that are frequently examined. Colder weather are found to be associated with decreasing travel volumes (Shih and Nichols, 2011; Tang and Thakuriah, 2012; Datla and Sharma, 2010). Wind is found to have both negative effect (Maze et al., 2006) and positive effect (Saneinejad et al., 2012) on car use or car traffic in different scenarios.

Compared to motorized travel modes, active modes including cycling and walking are considered more heavily affected by weather as the travelers would be entirely exposed to outdoor environment. For example, in terms of temperature difference due to seasonality, Muller et al. (2008) reported a threefold increase in cycling in summer warm weather over winter cold weather. Similar results are presented in some other studies confirming the temperature effect including positive effect of warmer weather on cycling (Bergström and Magnusson, 2003; Brandenburg et al., 2004) and negative effect of higher-than-threshold temperature on cycling and physical outdoor activity (Tu et al., 2004; Ahmed et al., 2010; Phung and Rose, 2007). Snowfall and rainfall are reported to be major factors hindering cycling (Bergström and Magnusson, 2003; Nankervis, 1999). Areas with higher annual precipitation are found to have lower level of cycling activities in different countries (Winters et al., 2007; Parkin et al., 2008). In particular, Phung and Rose (2007) found a non-linear relationship between rainfall and cycling activities with sharp decrease from no rain to light precipitation and marginal reduction from light to heavy rains. In addition, wind is found to deter cycling as well (Aaheim and Hauge, 2005; Flynn et al., 2012).

Apart from the travel demand or mode choice, the effects of weather on some other aspects of urban travel have also been explored. For example, Aaheim and Hauge (2005) found that travel distance would reduce if precipitation increases. On the other hand, they also reported that temperature increase would lead to travel distance increase for recreational purposes. Also, in regard to the system performance, Chapman et al. (2008) stated that variations in temperature that are larger than certain thresholds would lead to network delay in rail systems due to rail track distortions. In road transport, Eisenberg (2004) found a surprisingly negative effect of monthly precipitation on the fatal accident rate while a positive effect when measured daily. The author attributed this contrary to the negative lagged effect of precipitation across days.

\subsection{Impact of weather on public transit}

As mentioned earlier, the research effort spent on public transit in terms of the weather influence is relatively less compared to other modes. Khattak (1991) found that extreme weather would actually increase transit ridership by diverting travelers from car travel and active modes to public transit possibly due to difficulties to drive, cycle, or walk in extreme weather and a latter study by him and other researchers (Khattak et al., 1996) also found a similar trend. Changnon (1996) analyzed the effect of summer rainfall on weekday public transit travels and identified a slight decrease in ridership on rainy days. Cravo and Cohen (2009) explored the effect of various weather elements on transit ridership and revenue in New York City and reported a negative effect of rain and snow and a positive effect of below-normal temperature. Kalkstein et al. (2009), on the other hand, integrated different elements into a single variable termed 'air mass' and analyzed the impact of weather on transit ridership. They classified the air mass types and compared the ridership statistics across different classes. Their results suggest a higher ridership on dry days than on moist days.

In addition to the above studies that are largely based on survey-based methods, data from new sources such as smart card data have been utilized as well. For example, Hofmann and O'Mahony 
(2005) used the smart card data from Ireland to analyze the impact of rainfall on bus system performance in terms of service frequency, headway regularity and travel time variability. They found a negative effect of rainfall on ridership and frequency of service. Guo et al. (2007) took the Chicago Transit Authority as a case study and utilized a long-term smart card transaction data to analyze the weather impact on transit ridership. They found that different weather elements have effects in both directions on the daily ridership and most of them, including rainfall, snow, and wind, mainly have negative impacts. Similarly, Stover and McCormack (2012) and Kashfi et al. (2013) also focused on the impact of various weather conditions on daily ridership of public transit systems. Stover and McCormack (2012) found rainfall to be the most influential weather factor leading to ridership decrease and Kashfi et al. (2013) also found a strong relationship between rainfall and ridership decrease and they identified different levels of decrease on different days of the week. Arana et al. (2014) used smart card data and specifically targeted travel ridership on weekends under the assumption that trips on weekends are, to a much greater extent, discretionary in comparison. They investigated the impact of weather on weekend / recreational travel by public transit and found wind, rainfall, and cold temperature to be negatively associated with ridership. Most of these studies have focused on daily ridership statistics at city-wide scale and the weather elements are also generally averaged throughout the day.

As mentioned above, most existing studies on public transit either used traditional survey-based data with relatively small sample or focused on daily aggregate ridership with averaged weather conditions over the day of interest. This may mask the impact because the temporal variation within the day is not presented. Moreover, ridership seems to be the sole focus of the existing studies using smart card related. Few studies have been conducted at disaggregate or individual level. The work by Singhal et al. (2014) utilized hourly ridership statistics for the analysis on the system-level ridership. However, the spatially detailed and disaggregate analyses were not included. More detailed analyses at finer temporal and spatial resolution and investigation into the impacts of weather on the travel behavior of individual public transit users might be beneficial. This study is proposed to fill some of these gaps.

\section{THE STUDY CASE, DATA AND ANALYTICAL METHODS}

This study makes use of smart card data for public transit and meteorological records from Shenzhen, China for the entire month of September, 2014. In this section, we shall outline the geographical and meteorological background of Shenzhen as well its public transit systems. Details about the data and the analytical approach will also be provided.

\subsection{The Study Case}

Shenzhen is located in the Pearl River Delta, adjacent to Hong Kong Special Administrative Region. Since its establishment in 1979 as a Special Economic Zone (SEZ) of China, Shenzhen has become one of the largest and most developed cities in China. According to the Sixth Population Census (Shenzhen Statistics Department, 2015), Shenzhen is populated with over 10 million residents and has the population density of over five thousand people per square kilometres, making it one of the most densely populated cities in China and the world. There are a total of six districts under the city's jurisdiction: Luohu and Futian are the central urban districts with the longest development history; Nanshan and Yantian are the other two urban districts within the original SEZ boundary; Bao'an and Longgang form the suburban areas with four New District subordinate to them, namely Longhua, Pingshan, Dapeng, and Guangming. The city is situated in the subtropical monsoon climate region with a warm and humid climate. The yearly average temperature is about $23{ }^{\circ} \mathrm{C}$ and the yearly cumulative rainfall is around $1,935.8 \mathrm{~mm}$. For the month of September, the average daily temperature is $27.7^{\circ} \mathrm{C}$ with an average high of $31.1{ }^{\circ} \mathrm{C}$ and an average low of $25^{\circ} \mathrm{C}$. The average relative humidity is $78.8 \%$ and average monthly rainfall is $238.2 \mathrm{~mm}$.

Though, like other major Chinese cities, Shenzhen has experienced rapid growth of private car ownership and thus dramatic increase in the share of private car for daily trip making, public transport 
is still the major transport mode for daily trips for the majority of people in the city. Currently, the public transport system is mainly comprised of a total of 5 metro lines with 118 stations and more than 900 bus routes with 42,434 bus stops. In September 2014, the average daily ridership is 6.3 million for bus and 2.9 million for metro (Transport Commission of Shenzhen Municipality, 2015). The city is divided into 491 Traffic Analysis Zones. Figure 1 presents a map of Shenzhen showing the spatial configuration of the traffic zones, metro lines and stations, bus stops, and weather stations.

[Place Figure 1 about here]

The city of Shenzhen is an apt study area for our research owing to the prevalence of public transit usage, a relatively high percentage of trips made using smart card(as described later in Section 3.2), and a dense network of meteorological observation stations. September, 2014, with 22 weekdays and 8 weekend days, is chosen as the time period for this study primarily for two reasons. Firstly, we are interested in the impact of everyday weather conditions on public transit instead of extremely inclement weather events such as typhoon or thunderstorm. Weather in September varies in different elements such as temperature, humidity, and rainfall. There are no extremely disruptive metrological events recorded in September, 2014. Also, there are no major festivals or long holidays in September so the general travel characteristics would not be affected by those eventful occasions.

Based on the abovementioned weather and public transit travel characteristics, several hypotheses could be made in regard to the possible impact of daily weather on public transit usage. During late summer and early autumn (September in the Northern Hemisphere) in subtropical regions, average temperature would be relatively high and higher-than-average temperature would be even more unpleasant and could potentially reduce the desire to travel. Similarly, high humidity and air pressure are considered uncomfortable in a coastal and moist city like Shenzhen and would potentially reduce public transport ridership. Wind and rainfall may have a more complex effect. While rainfall is the most visible weather element among the selected and would undoubtedly cause inconvenience for travel in general, public transit ridership may not necessarily decrease largely because there may be a significant share of trips shifted from other modes (e.g. active modes) to public transit (Khattak, 1991). Likewise, a certain level of summer wind may be beneficial to outdoor activity participation which leads to increase in trip making but it may also become a hindering effect when demand is diverted from public transit to active modes or wind grows stronger to be considered unpleasant.

\subsection{Data}

The main datasets employed in this study consist of big data from two different sources: one-month public transport smart card transaction data for all cardholders and one-month meteorological observation data from all weather stations in Shenzhen. Supplementary data include the GPS trajectories of buses, location coordinates of all metro stations, bus stops, and weather stations, and the vector maps of Shenzhen District and Traffic Analysis Zones.

The smart card data contains all transactional records made by all card holders in Shenzhen during the month of September, 2014. Each transaction record represents a tapping-in or tapping-out action with detailed information on time and station for a metro trip or a boarding action with recorded time and vehicle number for a bus trip. By pairing tapping-in and tapping-out of a metro trip or matching the boarding record with the GPS trajectories of the bus for a bus trip, the spatial and temporal information on metro and bus trips are retrieved. This information includes the location and time of trip origin and destination. A total of $63,130,465$ bus trips and 42,159,992 metro trips are recovered for the entire month, resulting in daily average bus trip volume of 2.1 million (about $33.3 \%$ of the 6.3 million total daily bus trips in the city) and daily average metro trip volume of 1.4 million (about $48.3 \%$ of the 2.9 million total daily metro trips in the city). In other words, the smart card data cover onethird of all bus trips and nearly a half of all metro trips. 
The weather data are collected from the official website of Shenzhen Meteorological Bureau. There are a total of 157 operating weather observation stations in Shenzhen during the month of September, 2014 (as shown in Figure 1). Data concerning all major aspects of objective weather are collected. They include temperature, wind speed, humidity, rainfall, and air pressure. Spatial interpolation is applied to derive the exact weather condition at the very spots of trips. Interpolation with inverse distance weighting, which is extensively used in the field of meteorology, is applied (Jolly et al., 2005). It essentially takes the observations nearby and calculates the average value inversely weighted by the distance between the target location and the location of each observation.

Data are collected at a 1-minute interval for the entire month of September 2014 and eventually aggregated to the scale of an hourly average (or sum in the case of rainfall) for meaningful exploration. Among the objective elements involved, temperature is measured in Centigrade. Relative humidity is measured in percentage. Air pressure is measured in hundred Pascal. Wind speed is measured in meters per second and rainfall is measured in hourly cumulative millimetres.

\subsection{Analytical Methods}

This study aims to investigate the weather impacts on both public transit ridership and travel behavior of individual transit users. Our approach to investigating the impacts of weather on public transport ridership is to establish an association between weather conditions (temperature, wind speed, humidity, rainfall, and air pressure) during each hour of the day and the system-level (metro or bus) /stationlevel (for the metro system) ridership during the same hour by developing multivariate regression models. To control for the inherent temporal variations of transit ridership resulted from the temporality of daily activities, the deviation of ridership during a particular hour on a particular day from the monthly average during that hour is defined as the dependent variable. Specifically, the variable is defined by the following equation:

$$
\Delta Y_{i j}=Y_{i j}-\frac{\sum_{j=1}^{n} Y_{i j}}{n}
$$

where $Y_{i j}$ denotes the public transit ridership at the $i$ th hour on day $j$ of the month and $n$ is the total number of days, which can be 30 when developing a model for the entire month, 22 for weekdays and 8 for weekends, as will be explained later. Modeling on deviations helps effectively capture the impacts of weather on transit ridership, whilst the intra-day fluctuations in transit usage caused by the temporal patterns of daily activities are controlled for. The independent or explanatory variables include five weather variables including temperature, relative humidity, air pressure, wind speed, and rainfall. Meteorologically speaking, weather elements have a certain level of diurnal cycle caused by the rotation of the Earth (Weather Glossary, 2016). Similar to the ridership variable, weather variables have intrinsic temporal variations resulted from potential diurnal cycles and these variations should be accounted for in order to accurately capture the relationship between changes in weather and those in ridership. In this study, weather elements with distinct intra-day variations, i.e. temperature, relative humidity, and air pressure, are measured by deviations from the monthly average. Specifically, they are defined by the following equation:

$$
\Delta X_{i j}=X_{i j}-\frac{\sum_{j=1}^{n} X_{i j}}{n}
$$

where $X_{i j}$ denotes the observed weather (temperature, relative humidity, or air pressure) at the $i$ th hour on day $j$ of the month and $n$ is the total number of days, which equals to 30 in this study. As for the other two weather elements, namely wind speed and rainfall, they are relatively independent from the time of the day and thus are measured by absolute values.

Models are developed for the whole month, different types of days (i.e. weekdays and weekends), and different times of day on weekdays (peak hours and off-peak hours, identified via the distinct temporal distribution of trip making) to examine the possible differences in weather impacts on public 
transit ridership. The model specification is as follow.

$$
\Delta Y=\beta_{0}+\sum_{i}^{n} \beta_{i} D_{a y}+\beta_{t} \Delta T+\beta_{h} \Delta H+\beta_{p} \Delta P+\beta_{w} W+\beta_{r} R
$$

where $\Delta Y$ denotes the deviation of bus/metro hourly ridership on a particular day from the average on all days. $D a y_{i}$ are the day-of-week dummy variables. Similarly, $\Delta T, \Delta H$, and $\Delta P$ denote the deviations of the hourly temperature, relative humidity and air pressure on a particular day from the average on all days. $W$ and $R$ represent wind speed and rainfall respectively. Day-of-week variables are included to capture possible within group variations in different models (overall, weekday, weekend, or peak/off-peak hours).

As for the weather impact on the travel behavior of individual transit users, we shall investigate how public transit users adjust the frequency and pattern of trips made by public transport (sequence, location, mode, etc.) in response to changes in weather conditions. In order to identify the changes in trip patterns, we shall focus on regular public transit users who had on average at least two trips by public transport per day. Since it is more likely for people to maintain regular routines on weekdays, our analysis will focus on the 22 weekdays of the month. We intend to establish a link between the weather conditions experienced by the user on a day and the number of public transport trips and the regularity of the trips of the user on the same day. The trip patterns are represented in terms of trips in sequential order with location recorded at the TAZ (Traffic Analysis Zone) level and transport mode (either bus or metro) denoted. Figure 2 illustrates a hypothetical public transit user's trip patterns on different days. The trip patterns can be easily recovered from trip records using the smart card number as an identifier.

[Place Figure 2 about here]

The regularity of the trip pattern on a particular day is measured by its similarity with the pattern on each of the other 21 days. The similarity between the patterns on two days is based on the hourly pairwise comparison in terms of the existence, mode and location of a trip. A maximum score of similarity is given if a trip by the same mode is made during the same hour on both days. The score will be discounted if location or transport mode change is recorded. A similarity score between two days is derived by aggregating the hourly scores and the regularity of the trip pattern on a particular day is measured by the summation of that day's similarity scores to the other 21 days.

Multivariate regression models with the number and regularity of public transport trips as dependent variables are developed. The independent variables are daily weather conditions experienced by each individual at the actual locations of trip making, which are defined either in terms of observed absolute values (wind speed and rainfall) or relative values as deviations from the monthly average (temperature, relative humidity, and air pressure).

\section{RESULTS}

In this section, the modeling results concerning the impacts of weather on system-wide and stationlevel ridership as well as the travel patterns of individual transit users will be presented and discussed.

\subsection{Descriptive statistics}

Table 1 lists the descriptive statistics of dependent (ridership) and independent variables.

[Place Table 1 about here] 
As shown, variables for weather deviations (temperature, humidity, and air pressure) generally follow normal distribution as reported by their skewness and kurtosis. Both rainfall and wind speed are skewed, which is understandable especially for rainfall because of a large number of hours without recorded rainfall. Both variables are recoded into dummy variables that are more appropriate to account for the nature of the influence of wind and rainfall, which is more in kind, instead of magnitude. The weather dummy indicates whether or not it rain at a particular hour, whilst the wind speed dummy is defined based on the Beaufort wind force scale (Met Office, 2016) with wind scale over Level 3 (gentle breeze) coded as " 1 " and " 0 " otherwise.

Among all 540 hourly observations, 52 of them (close to 10\%) are with recorded rainfall. These rainfall observations are recorded on 13 different days (43.3\% of the 30 days in September). Among the raining hours, 48 of them are on weekdays (22 weekdays) and the other 4 are on weekends ( 8 weekends) and there are 11 out of the 66 identified peak hours (3 hours per weekday, see Section 4.2) with rainfall observations.

\subsection{Weather impacts on system-level ridership}

Two separate sets of models are developed for the two public transit systems respectively. Each set consists of five major models, which are the overall model and models for weekdays, weekends, peak hours, and off-peak hours respectively. The peak-hour models include observations during two identified peak-hour periods: a morning peak from 7 a.m. to 9 a.m. and an evening peak from 18 p.m. to 19 p.m. All other hours are off-peak hours.

In theory, different weather elements may have some degree of associations. For example, a high level of humidity and/or low air pressure may indicate precipitation; higher wind speed may be associated with higher precipitation (Raymond et al., 2003). Before we develop the multivariate analysis models, possible co-linearity between the weather variables is examined. Table 2 presents the examination results. The level of co-linearity is measured in a tolerance value. A rule-of-thumb threshold of tolerance is 0.2 and a value smaller than 0.2 indicates a serious co-linearity issue ( $\mathrm{O}^{\prime}$ brien, 2007). As shown in Table 2, all entries are largely over the threshold, suggesting that only trivia colinearity exists among the variables.

[Place Table 2 about here]

Table 3 presents the models for the bus system. From the goodness-of-fit and F-test statistics of models, we can see that most of models are statistically valid except for the peak-hour model. The explanatory power varies and models for weekends have higher $\mathrm{R}^{2}$ than the overall and weekday models do, indicating that weather impact accounts for a larger percentage of the variation in bus ridership on weekends than that on weekdays. The off-peak model has a high coefficient of determination. Table 3 shows that different weather elements have different impacts. In the overall model, only relative humidity is found to have significant impacts on ridership. In the weekday model, wind is found to have a significantly negative effect on bus ridership. In the weekend model, on the other hand, a number of weather variables are reported significant. Humidity has significant negative impacts on bus ridership and wind has a strong positive effect.

The peak hour and off-peak hour models show that weather plays more significant roles at off-peak hours than at peak hours. In the peak-hour model, no weather variables are found to be significant, nor is the model. During off-peak hours, on the other hand, weather plays much more significant roles. Increase in temperature, wind, and the presence of rainfall all have significantly negative effect on bus ridership. The effects of wind and rainfall, in particular, are very large in magnitude as they are considered major factors hindering outdoor walking. 
Place Table 3 about here]

The modeling results for the metro system are presented in Table 4. All models are significant except for the peak-hour model. The off-peak hour model has the highest explanatory power while difference in the coefficient of determination is not typically salient between overall and weekday/weekend models. Similar to the bus models, only humidity is found to be significant in the overall model with a negative impact on metro ridership. No weather elements, however, are found significant on weekdays. On weekends, humidity is also found to be the only influential element, which is in contrast to the results reported for the bus system.

The time-of-day models also give a slightly different result from that of the case for bus. During peak hours, none of the weather variables are significant to metro ridership. During off-peak hours, only rainfall, which is considered to be associated with discomfort while walking to the stations, is found to have significantly negative effect on metro ridership. This is different from that for the bus models. Temperature is not reported to be significant in any models.

[Place Table 4 about here]

Overall, increase in humidity is found to be negatively associated with public transit ridership, typically on weekends, as it is perceived as an uncomfortable and unpleasant weather condition. Wind shows opposite impacts for bus ridership on weekdays and on weekends, possibly due to the confounding effects between trip induction/reduction and mode shift from/to active mode or car. The presence of rainfall would negatively affect the public transit ridership during off-peak hours. Weather is found to be insignificant at peak hours for both modes since most commuting trips are largely mandatory and immune to external factors. On the contrary, weather influence is generally stronger during off-peak hours when trips are more discretionary in nature.

\subsection{Weather impacts on station-level ridership of the metro system}

To investigate the weather impacts on ridership at a finer spatial scale, models are developed for each station of the metro system. The modeling approach is similar to that of the system-level models: the deviation of ridership at a particular hour from the average during the same hour of the modeling period for each station is modeled on the weather conditions at the location of each station. There are 118 metro stations in Shenzhen and thus a total of 118 models are developed for weekdays and weekends respectively. A summary of the modeling results in terms of the number of stations found to be significantly affected by different weather elements is presented in Table 5 .

[Place Table 5 about here]

From Table 5, it is clear that the increase in most weather indicators has a negative effect on the ridership in many stations. On weekdays, the ridership in many stations is negatively affected by the increase in humidity, wind and the presence of rainfall. On weekends, on the other hand, the ridership is more extensively affected by high temperature, humidity and rainy weather and in more stations, the ridership is negatively affected. Interestingly, wind on weekends plays a more positive role in affecting metro usage in many stations, possibly because a certain level of breezing wind could mitigate the discomfort brought about by the high temperature and humidity in September in Shenzhen.

In terms of the spatial distribution of the significantly affected stations, Table 6 below demonstrates the regions where the significantly affected stations are located, classified as urban and suburban areas 
(see Section 3.1). It is clear that, for many weather elements, stations in urban areas are more vulnerable to weather variations. Typically, percentages of stations in urban areas that are significantly affected by humidity and wind are much larger than those in suburban areas, especially on weekends. Also, the percentages of unaffected stations are higher in suburban areas in all cases. Downtown areas and city centers are not only more densely populated but also equipped with more facilities for non-mandatory out-of-home activities. Participation in these activities is considered to be more intensely affected by weather. Thus, it is a reasonable result that downtown areas receive more influence from weather, especially on weekends during which more discretionary activities take place.

Place Table 6 about here]

\subsection{Weather impacts on the travel patterns of individual transit users}

We are also interested to know how experienced weather conditions influence the frequencies and patterns of public transport trips made by regular transit users. A total of 61,599 regular transit users are identified and included in the analysis. For each of the individuals, two models are developed: one for the impacts of weather on the patterns of trips made by public transport and one on the trip frequencies. The modeling results are classified according to the significance and the direction of influence of each experienced weather variable. Models about the weather impact on regularity are summarized in Table 7 and models for the weather impact on frequency are summarized in Table 8.

Place Table 7 about here]

Place Table 8 about here]

Table 7 shows that, in general, weather conditions affect the regularity of trip patterns of only a small percentage of regular transit users (maximally $12.5 \%$ of the individuals). More riders are likely to deviate from their routine trip patterns under the environment with lower-than-normal temperature, humidity and air pressure (significantly positive coefficients for $12.5 \%, 8.31 \%$ and $7.36 \%$ of the regular travelers respectively) compared to riders changing trip plan with increasing values in the three elements (significantly negative coefficients for $1.81 \%, 2.77 \%$ and $4.44 \%$ of the regular travelers respectively). For about $12.5 \%$ of the regular travelers, temperature increase has a positive effect on the regularity of trip patterns, implying that the decrease in temperature may lead to changes to their trip patterns. Similarly, for about $8.31 \%$ of the regular travelers, humidity decrease may motivate them to change their travel plans. Since the temperature and humidity are still high in September in Shenzhen, dropping temperature and humidity are generally considered more pleasant and welcome, which may invite changes to travel patterns. Wind speed and rainfall are found to significantly disrupt the trip patterns of about $2 \%$ and $3 \%$ of the regular travelers. Although the percentages are rather small, which might partly be due to a relatively low level of rainfall during the study period, some travelers do make distinctive changes under such weather conditions.

Table 8 shows that more users would actually increase the use of public transit under uncomfortable or adverse weather. More users would ride public transit more on hotter days compared to those who ride less. Rainfall and wind also contribute to higher rates of public transit usage for quite many users. This echoes with the results from Table 7 that more users would use public transit more regularly under hotter and more humid weather conditions. Wind and rainfall would typically increase the use of public transit for many users as walking or driving might be quite difficult under such conditions.

\section{SUMMARY AND DISCUSSION}

This study makes use of large-scale smart card records and voluminous meteorological observations, both in fine temporal and spatial resolutions, to explore the impact of everyday weather condition 
changes on the usage of public transit. Extending the existing literature, this study has established statistical associations between intra-day variations in public transit ridership, both system-wide and at station level, and the changes in weather conditions. Responses of regular transit users to weather condition changes in terms of trip patterns and trip frequencies have also been investigated.

The analytical results show that, in general, the increase in humidity, wind, and the existence of rainfall are associated with a certain degree of transit ridership decrease. The degree and the statistical significance of the impact vary from one element to another and also between the metro and bus systems. Humidity increase is reported to be negatively influential for both systems in general and on weekends. Wind has opposite effects for bus ridership on weekdays and on weekends, possibly attributed to a mutually counter effect between changes in trip demand and mode shift between public transit and other modes (e.g. active mode or car). Findings agree, to a large extent, with the general hypotheses that those considered unpleasant in summertime show negative influence on public transit ridership by reducing the desire to travel.

Results from the time-of-day models suggest that weather is much more influential during off-peak hours. No weather related variables are found to be significant during peak hours. During off-peak hours, however, the presence of rainfall is associated with ridership reduction in both systems and wind and temperature increase are associated with bus ridership decrease. These results suggest that commuting trips, which are mostly conducted during peak hours, are more resilient to weather influence.

Station-level models show that increase in the aforementioned weather elements have negative effects in many stations while positive effects appear in fewer stations. This finding coincides that of the system-level models where significant variables mostly have negative coefficients. Wind on weekends is an exception whose impact on metro ridership is positive in many stations. This is possibly because that summer breeze is considered by many to be a pleasant mitigation of heat and humidity for outdoor activity (Böcker et al., 2013). The spatial distribution of the significantly affected stations shows that more affected stations are located within the urban areas.

Generally speaking, results from the analysis on frequent travelers suggest that weather is not typically a strong influential factor in reshaping the daily travel routine of these travelers, indicating those who rely largely on public transit do not swing easily because of certain external changes due to the lack of alternatives, hence the term 'captive riders' (Krizek and El-Geneidy, 2007). In fact, more frequent riders would increase the use of public transit under adverse weather which is in agreement with the findings in some existing studies (Khattak, 1991; Singhal et al., 2014). Though the differentiation between regular and occasional travelers is, in a sense, vague and indefinite and the criterion for the selection is somehow arbitrary, the findings here would still provide a general perspective on how individual transit users might respond differently to weather variations. It is fundamentally an exploratory analytical result in hope of providing useful knowledge on how individuals respond to weather changes differently.

The findings of this study enrich the existing literature concerning the impacts of weather on public transport with empirical evidence derived from direct associations between ridership and weather conditions at much finer spatiotemporal scales (hourly and transit station-based ridership; individual transit users). These findings are highly relevant for public transport planning and management to address the issues and problems related to varying weather conditions.

The current study has several limitations. Firstly, there is no information on the route or the purpose of the trip in smart card data. This inherent flaw hinders a more in-depth exploration in terms of the impact of daily weather on different types of trips or the route choice. Supplementary data (e.g. comprehensive travel survey data) could be incorporated with large-scale smart card data as an attempt of addressing this deficiency. Secondly, data are confined to a single month period, which limits the potential of a longitudinal analysis with seasonality taken into account. This limitation also leads to a relatively small sample of rainfall observations, which hinders the finer exploration on the 
effect of rainfall at different levels. If data for longer period could be made available, the study can be extended to include seasonal variations so that a full temporal range of associations between public transit ridership and weather conditions can be established, which will generate more insight into the effect of weather on public transit and support short- to middle-term public transport planning and management. Thirdly, in addition to regular ones, occasional transit users should be included in the analysis about individuals' response to weather condition changes. Such an extension will help uncover the factors underlying the aggregate ridership changes to weather conditions. Moreover, how weather would affect mode shift from/to public transport to/from other transport modes deserves more research attention in the future to evaluate the impacts of long-term climate change on urban transportation. Last but not least, in future studies, qualitative methods could provide valuable insights into the mechanisms of the user responses towards weather variations and potential suggestions for the planners and managers to better schedule and operate public transit systems.

\section{ACKNOWLEDGEMENT}

This research was supported in part by the National Science Foundation of China (41171348, 41401444), A GRF project of the Hong Kong Research Grant Council (HKBU12656716), Natural Science Foundation of Shenzhen University (2016065), and Shenzhen Dedicated Funding of Strategic Emerging Industry Development Program (JCYJ20121019111128765). 


\section{REFERENCES}

Aaheim, H. A., \& Hauge, K. E. (2005) Impacts of climate change on travel habits: a national assessment based on individual choices. CICERO report.

Ahmed, F., Rose, G., \& Jacob, C. (2010) Impact of weather on commuter cyclist behaviour and implications for climate change adaptation. In Australasian Transport Research Forum (ATRF), 33rd, 2010, Canberra, ACT, Australia (Vol. 33).

Al Hassan, Y., \& Barker, D. J. (1999) The impact of unseasonable or extreme weather on traffic activity within Lothian region, Scotland. Journal of Transport Geography, 7(3), pp. 209-213.

Arana, P., Cabezudo, S., \& Peñalba, M. (2014) Influence of weather conditions on transit ridership: A statistical study using data from Smart cards. Transportation research part A: policy and practice, 59, pp. 1-12.

Bergström, A., \& Magnusson, R. (2003) Potential of transferring car trips to bicycle during winter. Transportation Research Part A: Policy and Practice, 37(8), pp. 649-666.

Böcker, L., Dijst, M., \& Prillwitz, J. (2013) Impact of everyday weather on individual daily travel behaviours in perspective: a literature review. Transport reviews, 33(1), pp. 71-91.

Brandenburg, C., Matzarakis, A., \& Arnberger, A. (2004) The effects of weather on frequencies of use by commuting and recreation bicyclists. Advances in tourism climatology, 12, pp. 189-197.

Call, D. A. (2011) The effect of snow on traffic counts in western New York State. Weather, Climate, and Society, 3(2), pp. 71-75.

Chan, C. B., \& Ryan, D. A. (2009) Assessing the effects of weather conditions on physical activity participation using objective measures. International journal of environmental research and public health, 6(10), pp. 2639-2654.

Changnon, S. A. (1996) Effects of summer precipitation on urban transportation. Climatic Change, 32(4), pp. 481-494.

Chapman, L., Thornes, J. E., Huang, Y., Cai, X., Sanderson, V. L., \& White, S. P. (2008) Modelling of rail surface temperatures: a preliminary study. Theoretical and Applied Climatology, 92(1-2), pp. 121-131.

Cohen, J. E., Williams, A., \& Cravo, V. (2009) The Impact of Weather on Transit Revenue in New York City, TRB Paper\# 09-3036. In 88th Annual Meeting of the Transportation Research Board. CD-ROM. Transportation Research Board of the National Academies, Washington DC.

Cools, M., Moons, E., Creemers, L., \& Wets, G. (2010) Changes in travel behavior in response to weather conditions: do type of weather and trip purpose matter? Transportation Research Record: Journal of the Transportation Research Board, 2157, pp. 22-28.

Datla, S., \& Sharma, S. (2010) Variation of impact of cold temperature and snowfall and their interaction on traffic volume. Transportation Research Record: Journal of the Transportation Research Board, 2169, pp. 107-115.

De Palma, A., \& Rochat, D. (1999) Understanding individual travel decisions: results from a commuters survey in Geneva. Transportation, 26(3), pp. 263-281.

Eisenberg, D. (2004) The mixed effects of precipitation on traffic crashes. Accident analysis \& prevention, 36(4), pp. 637-647.

Flynn, B. S., Dana, G. S., Sears, J., \& Aultman-Hall, L. (2012) Weather factor impacts on commuting to work by bicycle. Preventive Medicine, 54(2), pp. 122-124.

Guo, Z., Wilson, N., \& Rahbee, A. (2007) Impact of weather on transit ridership in Chicago, Illinois. Transportation Research Record: Journal of the Transportation Research Board, 2034, pp. 310.

Heinen, E., van Wee, B., \& Maat, K. (2010) Commuting by bicycle: an overview of the literature. Transport reviews, 30(1), pp. 59-96.

Hofmann, M. and O'Mahony, M. (2005) The impact of adverse weather conditions on urban bus performance measures. Proceedings of the 8th International IEEE Conference on Intelligent Transportation Systems, Vienna, Austria, pp. 431-436.

Jolly, W. M., Graham, J. M., Michaelis, A., Nemani, R., \& Running, S. W. (2005) A flexible, integrated system for generating meteorological surfaces derived from point sources across 
multiple geographic scales. Environmental modelling \& software, 20(7), pp. 873-882.

Kalkstein, A. J., Kuby, M., Gerrity, D., \& Clancy, J. J. (2009) An analysis of air mass effects on rail ridership in three US cities. Journal of transport geography, 17(3), pp. 198-207.

Kashfi, S., Lee, B., \& Bunker, J. M. (2013) Impact of rain on daily bus ridership: a Brisbane case study. In Australasian Transport Research Forum 2013 Proceedings. Australian Transportation Research Forum.

Keay, K., \& Simmonds, I. (2005) The association of rainfall and other weather variables with road traffic volume in Melbourne, Australia. Accident Analysis \& Prevention, 37(1), pp. 109-124.

Khattak, A. (1991) Driver Response to Unexpected Travel Conditions: Effect of Traffic Information and Other Factors. Ph.D. Thesis, Northwestern University, U.S.A.

Khattak, A., Polydoropoulou, A., \& Ben-Akiva, M. (1996) Commuters' Normal And Shift Decisions In Unexpected Congestion: Pre-trip Response To Advanced Traveler Information Systems. California Partners for Advanced Transit and Highways (PATH).

Koetse, M. J. and Rietveld, P. (2009) The impact of climate change and weather on transport: An overview of empirical findings. Transportation Research Part D: Transport and Environment, 14(3), pp. 205-221.

Krizek, K. J., \& El-Geneidy, A. (2007) Segmenting preferences and habits of transit users and nonusers. Journal of Public Transportation, 10(3), pp. 5.

Kyte, M., Khatib, Z., Shannon, P., \& Kitchener, F. (2001) Effect of weather on free-flow speed. Transportation research record: Journal of the transportation research board, 1776, pp. 6068.

Maze, T.H., Agarwal, M., \& Burchett, G.D. (2006) Whether weather matters to traffic demand, traffic safety, and traffic operations and flow. Transportation Research Record: Journal of the Transportation Research Board, 1948, pp. 170-176.

Met Office. (2016) "Beaufort wind force scale". [Online] Available from: http://www.metoffice.gov.uk/guide/weather/marine/beaufort-scale [Accessed 24th August 2016].

Muller, S., Tscharaktschiew, S., \& Haase, K. (2008) Travel-to-school mode choice modelling and patterns of school choice in urban areas. Journal of Transport Geography, 16, pp. 342-357.

Nankervis, M. (1999) The effect of weather and climate on bicycle commuting. Transportation Research Part A: Policy and Practice, 33(6), pp. 417-431.

O'brien, R. M. (2007) A caution regarding rules of thumb for variance inflation factors. Quality \& Quantity, 41(5), pp. 673-690.

Parkin, J., Wardman, M., \& Page, M. (2008) Estimation of the determinants of bicycle mode share for the journey to work using census data. Transportation, 35(1), pp. 93-109.

Phung, J., \& Rose, G. (2007) Temporal variations in usage of Melbourne's bike paths. In Proceedings of 30th Australasian Transport Research Forum, Melbourne: Forum papers (p. 1CD).

Raymond, D. J., Raga, G. B., Bretherton, C. S., Molinari, J., López-Carrillo, C., \& Fuchs, Ž. (2003) Convective forcing in the intertropical convergence zone of the eastern Pacific. Journal of the atmospheric sciences, 60(17), 2064-2082.

Shenzhen Statistics Department. (2015) "Bulletin of key statistics from the Sixth National Population Census in Shenzhen, 2010". [Online] Available from: http://www.sztj.gov.cn/xxgk/tjsj/pcgb/201105/t20110512_2061597.htm [Accessed 17th July 2015].

Shih, C., \& Nicholls, S. (2011) Modeling the influence of weather variability on leisure traffic. Tourism Analysis, 16(3), pp. 315-328.

Singhal, A., Kamga, C., \& Yazici, A. (2014) Impact of weather on urban transit ridership. Transportation research part A: policy and practice, 69, pp. 379-391.

Smith, B. L., Byrne, K. G., Copperman, R. B., Hennessy, S. M., \& Goodall, N. J. (2004) An investigation into the impact of rainfall on freeway traffic flow. 83rd annual meeting of the Transportation Research Board, Washington DC.

Spinney, J. E., \& Millward, H. (2011) Weather impacts on leisure activities in Halifax, Nova Scotia. International journal of biometeorology, 55(2), pp. 133-145.

Stover, V. W. and McCormack, E. D. (2012) The impact of weather on bus ridership in Pierce County, Washington. Journal of Public Transportation, 15(1), pp. 95-110. 
Tang, L. and Thakuriah, P.V. (2012) Ridership effects of real-time bus information system: A case study in the City of Chicago. Transportation Research Part C: Emerging Technologies, 22, pp. $146-161$.

Transport Commission of Shenzhen Municipality. (2015) "Quarterly report of transportation operating index statistics (3rd quarter, 2014)". [Online] Available from: http://www.sztb.gov.cn/xxgk/tjxx/201410/t20141013_45304.htm [Accessed 17th July 2015].

Tu, W., Stump, T. E., Damush, T. M., \& Clark, D. O. (2004) The effects of health and environment on exercise-class participation in older, urban women. Journal of aging and physical activity, 12, pp. 480-496.

Tucker, P., \& Gilliland, J. (2007) The effect of season and weather on physical activity: a systematic review. Public health, 121(12), pp. 909-922.

Weather Glossary. (2016) Weather Glossary: Diurnal Cycles. [Online] Available from: http://www.weatherdudes.com/glossary/D.html [Accessed 24th August 2016].

Winters, M., Friesen, M. C., Koehoorn, M., \& Teschke, K. (2007) Utilitarian bicycling: a multilevel analysis of climate and personal influences. American journal of preventive medicine, 32(1), pp. 52-58. 


\section{List of Figures}

Figure 1. The spatial configuration of traffic zones, metro lines and stations, bus lines and stops, and weather stations in Shenzhen

Figure 2. Trip patterns of a hypothetical transit user (Pi denotes places; X means no trip made)

\section{List of Tables}

Table 1. Descriptive statistics of variables

Table 2. Co-linearity among the weather variables measured in the value of tolerance

Table 3. Model results for the bus system

Table 4. Model results for the metro system

Table 5. Summary of station-level modeling results

Table 6. Spatial distribution of significantly affected stations

Table 7. Weather impact on the regularities of public transport trips made by regular transit users

Table 8 . Weather impact on the frequencies of public transport trips made by regular transit users

\section{List of Keywords:}

weather condition

public transit

ridership

smart card data

Shenzhen 


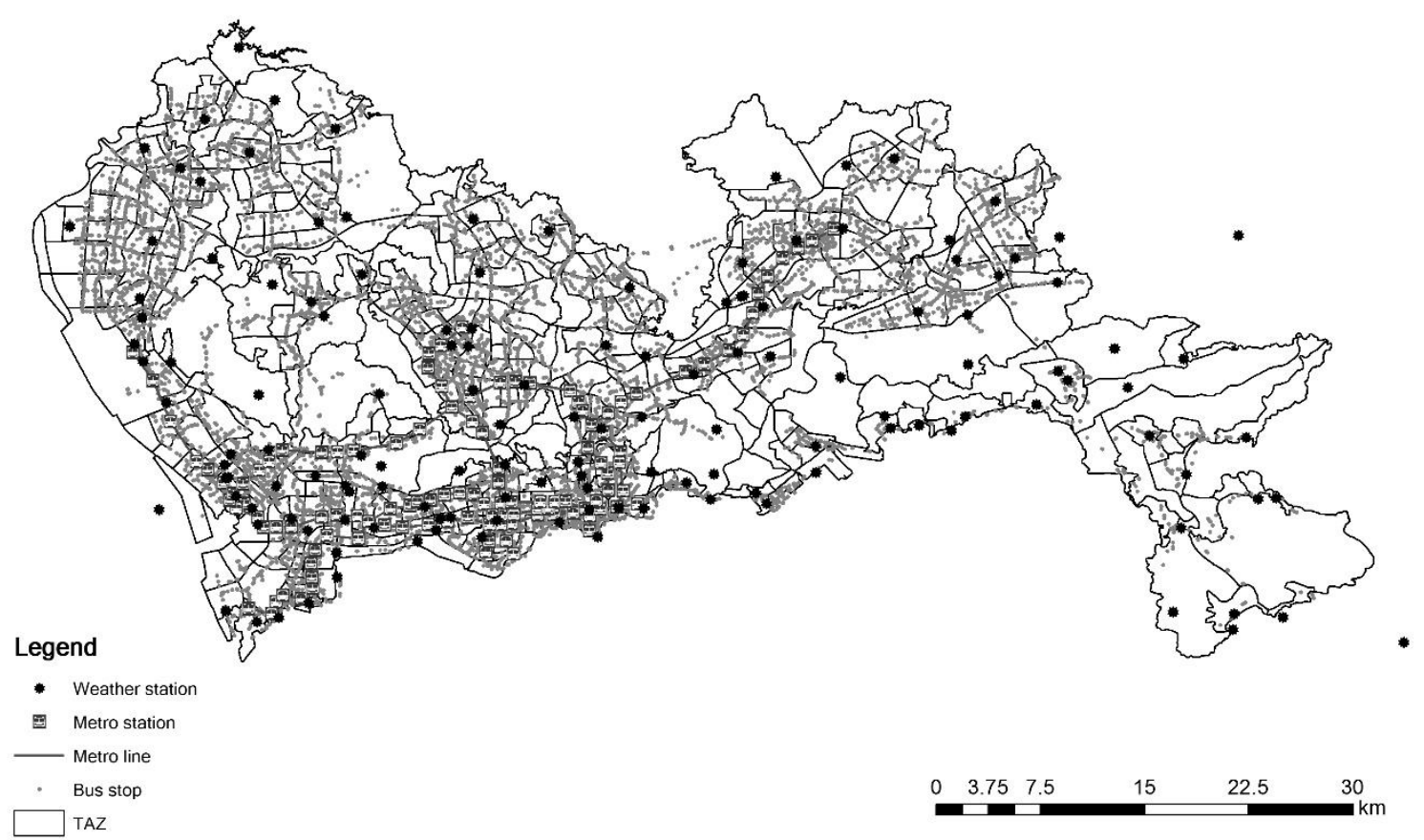

Figure 1. The spatial configuration of traffic zones, metro lines and stations, bus lines and stops, and weather stations in Shenzhen

\begin{tabular}{|lllllll|}
\hline Day/Hour & $\ldots$ & 7 a.m. & 8 a.m. & 9 a.m. & 10 a.m. & $\ldots$ \\
Day 1 & $\ldots$ & $\mathrm{P}_{1}$ (Bus) & $\mathrm{X}$ & $\mathrm{X}$ & $\mathrm{P}_{2}$ (Bus) & $\ldots$ \\
Day 2 & $\ldots$ & $\mathrm{P}_{1}$ (Bus) & $\mathrm{X}$ & $\mathrm{X}$ & $\mathrm{P}_{2}$ (Bus) & $\ldots$ \\
Day 3 & $\ldots$ & $\mathrm{P}_{1}$ (Metro) & $\mathrm{X}$ & $\mathrm{X}$ & $\mathrm{P}_{2}$ (Bus) & $\ldots$ \\
Day 4 & $\ldots$ & $\mathrm{P}_{3}$ (Bus) & $\mathrm{X}$ & $\mathrm{X}$ & $\mathrm{P}_{4}$ (Bus) & $\ldots$ \\
Day 5 & $\ldots$ & $\mathrm{X}$ & $\mathrm{P}_{1}$ (Bus) & $\mathrm{X}$ & $\mathrm{X}$ & $\ldots$ \\
$\ldots$ & $\ldots$ & $\ldots$ & $\ldots$ & $\ldots$ & $\ldots$ & $\ldots$ \\
\hline
\end{tabular}

Figure 2. Trip patterns of a hypothetical transit user ( $\mathrm{P}_{\mathrm{i}}$ denotes places; $\mathrm{X}$ means no trip made $)$

Table 1. Descriptive statistics of variables

\begin{tabular}{|c|c|c|c|c|c|c|}
\hline Overall $(\mathrm{N}=540)$ & Minimum & Maximum & Mean & Std. Deviation & Skewness & Kurtosis \\
\hline$\Delta \mathrm{Bus}$ & $-120,050.25$ & $85,525.75$ & 0.00 & $19,516.35$ & -0.97 & 7.90 \\
\hline$\Delta$ Metro & $-29,160.00$ & $31,558.00$ & 0.00 & $7,048.77$ & 0.15 & 3.29 \\
\hline$\Delta \mathrm{T}\left({ }^{\circ} \mathrm{C}\right)$ & -4.99 & 3.81 & 0.00 & 1.26 & -0.27 & 0.97 \\
\hline$\Delta \mathrm{H}(\%)$ & -17.30 & 26.64 & 0.00 & 6.97 & -0.02 & 0.62 \\
\hline$\Delta \mathbf{P}(\mathbf{h P a})$ & -9.02 & 5.16 & 0.00 & 2.90 & -0.40 & 0.06 \\
\hline Wind speed $(\mathrm{m} / \mathrm{s})$ & 0.37 & 7.44 & 1.85 & 1.05 & 1.73 & 4.33 \\
\hline Rainfall (mm) & 0.00 & 29.00 & 0.28 & 1.97 & 11.72 & 156.00 \\
\hline Weekday $(\mathrm{N}=396)$ & Minimum & Maximum & Mean & Std. Deviation & Skewness & Kurtosis \\
\hline$\Delta \mathrm{Bus}$ & $-78,833.73$ & $42,846.27$ & 0.00 & $15,426.32$ & -1.92 & 6.64 \\
\hline$\Delta$ Metro & $-26,622.95$ & $31,558.00$ & 0.00 & $6,685.74$ & 0.40 & 3.94 \\
\hline$\Delta \mathrm{T}\left({ }^{\circ} \mathrm{C}\right)$ & -4.99 & 3.81 & 0.08 & 1.23 & -0.14 & 1.59 \\
\hline
\end{tabular}




\begin{tabular}{|c|c|c|c|c|c|c|}
\hline$\Delta H(\%)$ & -17.30 & 26.64 & 0.55 & 6.79 & -0.00 & 0.88 \\
\hline$\Delta \mathbf{P}(\mathbf{h P a})$ & -9.02 & 5.16 & 0.47 & 2.97 & -0.87 & 0.80 \\
\hline Wind speed $(\mathrm{m} / \mathrm{s})$ & 0.37 & 7.44 & 1.85 & 1.11 & 1.84 & 4.57 \\
\hline Rainfall (mm) & 0.00 & 29.00 & 0.31 & 1.84 & 11.38 & 159.67 \\
\hline Weekend $(\mathrm{N}=144)$ & Minimum & Maximum & Mean & Std. Deviation & Skewness & Kurtosis \\
\hline$\Delta \mathrm{Bus}$ & $-120,050.25$ & $85,525.75$ & 0.00 & $27,898.41$ & -0.36 & 4.54 \\
\hline$\Delta$ Metro & $-29,160.00$ & $21,833.00$ & 0.00 & $7,987.83$ & -0.26 & 2.11 \\
\hline$\Delta \mathrm{T}\left({ }^{\circ} \mathrm{C}\right)$ & -3.69 & 2.36 & -0.23 & 1.30 & -0.57 & -0.67 \\
\hline$\Delta H(\%)$ & -17.14 & 21.26 & -1.51 & 7.24 & 0.03 & 0.15 \\
\hline$\Delta \mathbf{P}(\mathbf{h P a})$ & -5.37 & 4.35 & -1.28 & 2.29 & 1.12 & 1.06 \\
\hline Wind speed $(\mathrm{m} / \mathrm{s})$ & 0.72 & 4.23 & 1.87 & 0.85 & 0.89 & 0.02 \\
\hline Rainfall (mm) & 0.00 & 27.70 & 0.21 & 2.32 & 11.84 & 141.25 \\
\hline Peak-hour $(\mathrm{N}=66)$ & Minimum & Maximum & Mean & Std. Deviation & Skewness & Kurtosis \\
\hline$\Delta B u s$ & $-78,833.73$ & $42,846.27$ & 0.00 & $26,367.57$ & -1.63 & 2.23 \\
\hline$\Delta$ Metro & $-26,622.95$ & $17,532.45$ & 0.00 & $9,033.92$ & -0.53 & 0.94 \\
\hline$\Delta \mathrm{T}\left({ }^{\circ} \mathrm{C}\right)$ & -4.44 & 3.61 & 0.07 & 1.69 & -0.39 & 0.19 \\
\hline$\Delta H(\%)$ & -17.30 & 22.55 & 0.34 & 8.82 & 0.35 & 0.07 \\
\hline$\Delta \mathbf{P}(\mathbf{h P a})$ & -8.16 & 4.64 & 0.44 & 2.86 & -0.87 & 0.85 \\
\hline Wind speed $(\mathrm{m} / \mathrm{s})$ & 0.37 & 6.08 & 2.22 & 1.11 & 0.86 & 1.07 \\
\hline Rainfall (mm) & 0.00 & 2.20 & 0.10 & 0.36 & 4.68 & 22.97 \\
\hline Off-peak $(\mathrm{N}=330)$ & Minimum & Maximum & Mean & Std. Deviation & Skewness & Kurtosis \\
\hline$\Delta \mathrm{Bus}$ & $-60,614.27$ & $32,977.23$ & 0.00 & $12,179.95$ & -1.48 & 5.28 \\
\hline$\Delta$ Metro & $-22,711.00$ & $31,588.00$ & 0.00 & $6,127.17$ & 0.96 & 5.32 \\
\hline$\Delta \mathrm{T}\left({ }^{\circ} \mathrm{C}\right)$ & -4.99 & 3.81 & 0.09 & 1.12 & 0.05 & 1.88 \\
\hline$\Delta H(\%)$ & -15.62 & 26.64 & 0.59 & 6.32 & -0.17 & 1.02 \\
\hline$\Delta \mathbf{P}(\mathbf{h P a})$ & -9.02 & 5.16 & 0.47 & 2.99 & -0.87 & 0.82 \\
\hline Wind speed $(\mathbf{m} / \mathbf{s})$ & 0.38 & 7.44 & 1.77 & 1.10 & 2.11 & 5.94 \\
\hline Rainfall (mm) & 0.00 & 29.00 & 0.35 & 2.00 & 10.47 & 134.48 \\
\hline
\end{tabular}

Notes: a). Ridership is counted hourly; b). Definitions of key variables: $\Delta$ Bus: deviation of bus ridership; $\Delta$ Metro: deviation of metro ridership; $\Delta \mathrm{T}$ : temperature deviation; $\Delta \mathrm{H}$ : humidity deviation; $\Delta \mathrm{P}$ : air pressure deviation.

Table 2. Co-linearity among the weather variables measured in the value of tolerance

\begin{tabular}{cccccc}
\hline Model/variable & Overall & Weekday & Weekend & Peak & Off-peak \\
\hline$\Delta \mathrm{T}$ & 0.81 & 0.61 & 0.80 & 0.35 & 0.79 \\
$\Delta \mathrm{H}$ & 0.69 & 0.57 & 0.56 & 0.30 & 0.66 \\
$\Delta \mathrm{P}$ & 0.62 & 0.62 & 0.82 & 0.62 & 0.66 \\
$\mathrm{~W}$ & 0.69 & 0.67 & 0.72 & 0.87 & 0.84 \\
$\mathrm{R}$ & 0.60 & 0.59 & 0.69 & 0.51 & 0.63
\end{tabular}

Notes: Definitions of variables: $\Delta \mathrm{T}$ : temperature deviation; $\Delta \mathrm{H}$ : humidity deviation; $\Delta \mathrm{P}$ : air pressure deviation; $\mathrm{W}$ : binary for wind; $\mathrm{R}$ : binary for rainfall

Table 3. Model results for the bus system

\begin{tabular}{lccccc}
\hline Variable & Overall & Weekday & Weekend & Peak-hour & Off-peak \\
\hline Intercept & 641.48 & 2508.31 & 3171.66 & -428.24 & $2987.21^{* * *}$ \\
Tue. & $-7891.06^{* *}$ & $-9027.74^{* *}$ & - & -4714.10 & $-9885.82^{* *}$ \\
Wed. & -510.52 & -1965.24 & - & 710.71 & -2404.39 \\
Thu. & 4626.25 & 1206.75 & - & 12224.09 & -573.03 \\
Fri. & $6581.54^{* *}$ & $6412.06^{* *}$ & - & 4043.06 & $6252.01^{* *}$ \\
Sat. & $6970.66^{* *}$ & - & Ref. & - & - \\
Sun. & $-10053.22^{* *}$ & - & $-13303.63^{* *}$ & - & - \\
$\Delta \mathrm{T}$ & -206.45 & 697.95 & $2930.12^{*}$ & 358.11 & $-1294.90^{* * *}$ \\
\hline
\end{tabular}




\begin{tabular}{lccccc}
\hline$\Delta \mathrm{H}$ & $-561.86^{* *}$ & -59.78 & $-1464.10^{* * *}$ & -168.29 & -95.52 \\
$\Delta \mathrm{P}$ & -43.59 & -207.33 & -37.96 & -1700.12 & 138.03 \\
$\mathrm{~W}$ & -541.00 & $-7747.94^{* *}$ & $18704.42^{* *}$ & -11384.93 & $-5615.27^{* *}$ \\
$\mathrm{R}$ & -624.21 & -2877.04 & 21606.45 & 6455.28 & $-5708.67^{* *}$ \\
Obs. & 540 & 396 & 144 & 66 & 330 \\
Adj. $\mathrm{R}^{2}$ & 0.13 & 0.13 & 0.23 & 0.04 & 0.27 \\
F stats & $8.19(0.000)$ & $7.66(0.007)$ & $8.08(0.000)$ & $0.72(0.691)$ & $14.74(0.000)$ \\
\hline
\end{tabular}

Notes: a). Dependent variable: deviation of hourly bus ridership; b). Definitions of some independent variables: $\Delta \mathrm{T}$ : temperature deviation; $\Delta \mathrm{H}$ : humidity deviation; $\Delta \mathrm{P}$ : air pressure deviation; $\mathrm{W}$ : binary for wind; R: binary for rainfall; c). ${ }^{* *}$ significant at 0.05 level and "significant at 0.1 level.

Table 4. Model results for the metro system

\begin{tabular}{lccccc}
\hline Variable & Overall & Weekday & Weekend & Peak-hour & Off-peak \\
\hline Intercept & $-1279.40^{*}$ & -877.88 & 225.89 & -1040.03 & -940.57 \\
Tue. & $-1747.26^{*}$ & $-1930.60^{* *}$ & - & -2440.25 & $-1848.84^{* *}$ \\
Wed. & $2181.43^{* *}$ & $1942.41^{* *}$ & - & 1540.09 & $2114.27^{* *}$ \\
Thu. & $2261.32^{* *}$ & 1541.78 & - & 3675.71 & 1280.50 \\
Fri. & $7620.92^{* *}$ & $7641.07^{* *}$ & - & 5976.41 & $7956.24^{* *}$ \\
Sat. & $2488.24^{* *}$ & - & Ref. & - & - \\
Sun. & -832.60 & - & $-2420.79^{*}$ & - & - \\
$\Delta \mathrm{T}$ & -386.51 & -293.74 & 525.35 & -774.26 & -147.55 \\
$\Delta \mathrm{H}$ & $-177.59^{* *}$ & -74.05 & $-405.27^{* *}$ & -322.77 & -45.93 \\
$\Delta \mathrm{P}$ & -84.34 & -138.36 & -51.77 & -912.20 & -7.20 \\
$\mathrm{~W}$ & 148.79 & -1333.42 & 3915.44 & -795.92 & -961.66 \\
$\mathrm{R}$ & -931.64 & -1642.70 & 5594.46 & 2684.29 & $-2862.90^{* *}$ \\
Obs. & 540 & 396 & 144 & 66 & 330 \\
Adj. $\mathrm{R}^{2}$ & 0.17 & 0.21 & 0.15 & 0.07 & 0.29 \\
F stats & $11.06(0.000)$ & $12.62(0.001)$ & $5.18(0.000)$ & $1.58(0.143)$ & $15.55(0.000)$ \\
\hline Notes: & Dep & & & &
\end{tabular}

Notes: a). Dependent variable: Derivation of hourly metro ridership; b). Definitions of some independent variables: $\Delta \mathrm{T}$ : temperature deviation; $\Delta \mathrm{H}$ : humidity deviation; $\Delta \mathrm{P}$ : air pressure deviation; W: binary for wind; R: binary for rainfall; c). ${ }^{* *}$ significant at 0.05 level and *significant at 0.1 level.

Table 5. Summary of station-level modeling results

\begin{tabular}{|c|c|c|c|c|c|c|}
\hline Element & \multicolumn{2}{|c|}{ Overall } & \multicolumn{2}{|c|}{ Weekdays } & \multicolumn{2}{|c|}{ Weekends } \\
\hline & Positive & Negative & Positive & Negative & Positive & Negative \\
\hline$\Delta \mathrm{T}$ & 3 & 10 & 9 & 2 & 1 & 26 \\
\hline$\Delta \mathrm{H}$ & 0 & 52 & 0 & 24 & 6 & 34 \\
\hline$\Delta \mathrm{P}$ & 11 & 11 & 14 & 11 & 2 & 12 \\
\hline W & 1 & 34 & 0 & 52 & 13 & 0 \\
\hline $\mathrm{R}$ & 0 & 49 & 0 & 39 & 1 & 12 \\
\hline None & \multicolumn{2}{|c|}{20} & \multicolumn{2}{|c|}{33} & \multicolumn{2}{|c|}{27} \\
\hline
\end{tabular}

Note: Entries of the table are the numbers of stations found to be significantly affected by relevant weather elements.

Table 6. Spatial distribution of significantly affected stations

\begin{tabular}{|c|c|c|c|c|c|c|c|c|c|c|c|c|}
\hline & \multicolumn{4}{|c|}{ Overall } & \multicolumn{4}{|c|}{ Weekdays } & \multicolumn{4}{|c|}{ Weekends } \\
\hline & \multicolumn{2}{|c|}{ Urban (\%) } & \multicolumn{2}{|c|}{ Suburban (\%) } & \multicolumn{2}{|c|}{ Urban $(\%)$} & \multicolumn{2}{|c|}{ Suburban (\%) } & \multicolumn{2}{|c|}{ Urban (\%) } & \multicolumn{2}{|c|}{ Suburban (\%) } \\
\hline$\Delta \mathrm{T}$ & 11 & 15.07 & 2 & 4.44 & 7 & 9.59 & 4 & 8.89 & 13 & 17.81 & 14 & 31.11 \\
\hline$\Delta \mathrm{H}$ & 40 & 54.79 & 12 & 26.67 & 17 & 23.29 & 7 & 15.56 & 36 & 49.32 & 4 & 8.89 \\
\hline$\Delta \mathrm{P}$ & 14 & 19.18 & 8 & 17.78 & 14 & 19.18 & 11 & 24.44 & 12 & 16.44 & 2 & 4.44 \\
\hline W & 27 & 36.99 & 8 & 17.78 & 39 & 53.42 & 13 & 28.89 & 9 & 12.33 & 4 & 8.89 \\
\hline $\mathrm{R}$ & 24 & 32.88 & 25 & 55.56 & 19 & 26.03 & 20 & 44.44 & 6 & 8.22 & 7 & 15.56 \\
\hline
\end{tabular}




\begin{tabular}{lcccccccccccc}
\hline None & 12 & 16.44 & 8 & 17.78 & 20 & 27.40 & 13 & 28.89 & 12 & 16.44 & 15 & 33.33 \\
Total & 73 & 100.00 & 45 & 100.00 & 73 & 100.00 & 45 & 100.00 & 73 & 100.00 & 45 & 100.00
\end{tabular}

Note: Entries of the table are the numbers of stations found to be significantly affected by relevant weather elements in different district areas and the percentages against the total numbers of stations in corresponding areas, in \%.

Table 7. Weather impact on the regularities of public transport trips made by regular transit users

\begin{tabular}{lcccc}
\hline & Number and percentage of individuals that are significantly affected \\
\hline Element & Positively & Percentage & Negatively & Percentage \\
Temp. increase & 7,701 & $12.50 \%$ & 1,113 & $1.81 \%$ \\
Humid. increase & 5,120 & $8.31 \%$ & 1,707 & $2.77 \%$ \\
Press. increase & 4,535 & $7.36 \%$ & 2,733 & $4.44 \%$ \\
Wind speed & - & - & 1,268 & $2.06 \%$ \\
Rainfall & - & - & 2,043 & $3.32 \%$ \\
\hline
\end{tabular}

Note: ${ }^{*}$ at $5 \%$ significant level

Table 8. Weather impact on the frequencies of public transport trips made by regular transit users

\begin{tabular}{lcccc}
\hline & \multicolumn{3}{c}{ Number and percentage of individuals that are significantly affected } \\
\hline Element & Positively & Percentage & Negatively & Percentage \\
Temp. increase & 6,718 & $10.91 \%$ & 1,682 & $2.73 \%$ \\
Humid. increase & 3,068 & $4.98 \%$ & 3,342 & $5.43 \%$ \\
Press. increase & 5,735 & $9.31 \%$ & 2,018 & $3.28 \%$ \\
Wind speed & 25,586 & $41.54 \%$ & 960 & $1.56 \%$ \\
Rainfall & 12,835 & $20.84 \%$ & 845 & $1.37 \%$ \\
\hline
\end{tabular}

Note: ${ }^{*}$ at $5 \%$ significant level 